\title{
NOVO MODELO DE GESTÃO PARA HOSPITAIS UNIVERSITÁRIOS: PERCEPÇÃO DOS PROFISSIONAIS DE SAÚDE
}

New management model for University Hospitals: perception of health professionals

\author{
Kedna Kelly de Souza Gomes ${ }^{1}$ \\ Lúcia Conde de Oliveira ${ }^{2}$ \\ Ana Karla Batista Bezerra Zanella ${ }^{3}$ \\ Lúcia de Fátima Rocha Bezerra Maia ${ }^{4}$
}

\section{Resumo}

Objetivou-se analisar a percepção dos profissionais de saúde, de um Hospital Universitário, sobre a Empresa Brasileira de Serviços Hospitalares (EBSERH) na gestão do referido hospital. Trata-se de uma pesquisa de natureza qualitativa, na qual se utilizaram como técnica para a coleta de dados a observação simples e a entrevista semiestruturada: a interpretação dos dados baseou-se na análise dos temas trazidos pelos discursos. Identificaram-se fragilidades no processo de adesão da instituição à EBSERH, o qual vem ocorrendo de forma gradual e silenciosa; a discussão sobre ela está no nível mais de questionamentos do que de afirmativas, sendo uma proposta em andamento, sem a participação dos trabalhadores e da comunidade, contrariando o princípio constitucional da participação.

Palavras-chave: Privatização. Sistema Único de Saúde. Hospitais Universitários. Gestão Hospitalar.

\begin{abstract}
This study aimed to analyze the perception of health professionals, a university hospital, on the Brazilian Hospital Services (EBSERH) on management of the hospital. This is a qualitative research, which is used as a technique for data collection simple observation and semistructured interviews; data interpretation was based on the analysis of the issues brought by the speeches. We identified weaknesses in the institution subscribes to EBSERH process which has been occurring gradually and quietly, the discussion about it is at the level of questioning than affirmative, with a proposal in progress without the participation of workers and community, contrary to the constitutional principle of participation.
\end{abstract}

Keywords: Privatization. Unified Health System. University Hospitals. Hospital Administration.

\footnotetext{
${ }^{1}$ Assistente Social especialista em Atenção Hospitalar à Saúde - Saúde da Mulher e da Criança, na modalidade de Residência Multiprofissional, pela Universidade Federal do Ceará (UFC). Maternidade Escola Assis Chateaubriand (MEAC). Telefone 085 87898204. E-mail: kednasousa@yahoo.com.br. ${ }^{2}$ Assistente Social. Doutora em Saúde Coletiva pela Universidade do Estado do Rio de Janeiro. Professora adjunta da Universidade Estadual do Ceará (UECE).

${ }^{3}$ Assistente Social da Universidade Federal do Ceará e da Prefeitura Municipal de Fortaleza, mestre em Políticas Públicas pela Universidade Estadual do Ceará - UECE.

${ }^{4}$ Assistente Social da Universidade Federal do Ceará. Mestre em Administração pela Universidade Federal do Ceará (UFC).

Serv. Soc. \& Saúde, Campinas, SP v. 13, n. 2 (18) p. 283-298 jul./dez. 2014 ISSN 1676-6806
} 


\section{INTRODUÇÃO}

O contexto do neoliberalismo ${ }^{5}$ traz entre suas diretrizes a orientação de promover um processo de contrarreforma do Estado, inaugurado no Brasil na década de 1990 e implementado de forma mais efetiva no governo de Fernando Henrique Cardoso (FHC), na contramão da conquista de direitos alcançados com a Constituição de 1988. Isto tem provocado mudanças constitucionais significativas, sobretudo o desmonte dos direitos sociais e das políticas sociais públicas.

Conservando elementos de continuidade com o governo FHC, em particular com o Plano Diretor da Reforma do Estado, presidida pelo então ministro de Estado, Bresser Pereira $^{6}$, foi criada a Empresa Brasileira de Serviços Hospitalares (EBSERH). Referida empresa faz parte de um conjunto de medidas adotadas desde o início do governo Lula e mantidas no atual de Dilma Rousseff, que se propôs a operar a contrarreforma do Estado (MARCH, 2012).

A criação da EBSERH está assentada no discurso ideológico de que a crise na saúde advém da má gestão dos serviços. Por isso, faz-se necessário reestruturar o Estado com vistas a se tornar eficiente e de qualidade, introduzindo mecanismos de mercado na gestão pública.

Diante desse contexto social e político, o artigo pretende apresentar os resultados e as discussões advindas de uma pesquisa na qual buscamos investigar a percepção dos profissionais de saúde de um Hospital Universitário, em Fortaleza/CE, acerca da proposta de instauração da mencionada empresa para a gestão dos hospitais universitários. A escolha por esse objeto adveio da experiência na Residência Multiprofissional em atenção hospitalar à saúde na área de concentração Saúde da Mulher e da Criança no Hospital Universitário, que proporcionou o contato direto com a política de saúde e as implicações no seu processo de privatização. Em face disso, tentamos analisar a visão dos profissionais de saúde a respeito dessa proposta de gestão bastante complexa e polêmica entre os distintos segmentos da sociedade.

\footnotetext{
5 “O neoliberalismo nasceu logo depois da II Guerra Mundial, na região da Europa e da América do Norte onde imperava o capitalismo. Foi uma reação teórica e política veemente contra o Estado intervencionista e de bem-estar" (ANDERSON, 1995, p. 09). Todavia, as ideias neoliberais no cenário brasileiro somente se efetivaram na década de 1990.

${ }^{6}$ Bresser Pereira foi ministro da Administração Federal e Reforma do Estado (MARE) nos primeiros quatro anos (1994-1998) do governo Fernando Henrique Cardoso.

Serv. Soc. \& Saúde, Campinas, SP v. 13, n. 2 (18) p. 283-298 jul./dez. 2014 ISSN 1676-6806
} 


\section{Trajetória metodológica da pesquisa}

Trata-se de pesquisa de natureza qualitativa, tendo em vista ser uma necessidade do próprio objeto. Traçamos como objetivo geral analisar a percepção dos profissionais de saúde de um Hospital Universitário, em Fortaleza/CE, sobre a instauração da EBSERH para gerir os hospitais universitários. Dessa forma, atende o intuito da natureza da pesquisa qualitativa, definida, segundo Martinelli (1999), por trazer à tona as opiniões dos participantes a respeito do que está sendo pesquisado, ou seja, não é só a visão do pesquisador que irá nortear a pesquisa, mas também a dos sujeitos.

Realizamos um levantamento documental da legislação em relação ao tema. $\mathrm{Na}$ pesquisa de campo, utilizamos como técnica para coleta de dados a observação simples e a entrevista semiestruturada gravada. Entrevistamos dez profissionais de nível superior integrantes da equipe multiprofissional da instituição, dentre as seguintes categorias profissionais: Assistentes Sociais, Enfermeiros, Psicólogos, Médicos, Farmacêuticos, Nutricionistas e Fisioterapeutas. Destes, sete eram servidores públicos federais e três eram celetistas ${ }^{7}$.

Como critérios adotados para a escolha dos sujeitos da pesquisa constaram os seguintes: ser profissional de nível superior e ter vínculo empregatício regulamentado. Foram excluídos, então, os residentes e os demais profissionais sem vínculo empregatício e os que não aceitaram participar da pesquisa. Após o levantamento dos dados, procedemos com a sistematização destes e posteriormente com a análise dos temas trazidos pelos sujeitos da pesquisa.

Em atendimento ao exigido, a pesquisa foi submetida ao Comitê de Ética e Pesquisa da instituição, tendo sido aprovada conforme parecer $n^{\circ}$ 407.993. Desta forma, buscamos seguir os preceitos éticos da Resolução do Conselho Nacional de Saúde 466/2012, que regulamenta a pesquisa com seres humanos. Como determinam os princípios éticos, mantivemos o anonimato dos participantes e, para tal, lhes atribuímos a palavra entrevistado, seguida do número de entrada. Assim, entrevistado 1, 2 ... 10.

\footnotetext{
${ }^{7}$ Contratados por uma entidade de natureza privada.

Serv. Soc. \& Saúde, Campinas, SP v. 13, n. 2 (18) p. 283-298 jul./dez. 2014 ISSN 1676-6806
} 


\section{A privatização do SUS e a criação da EBSERH}

A partir da década de $1990^{8}$, no Brasil, assistimos ao avanço das ações de contrarreformas conservadoras, as quais só postergam os avanços conquistados na Constituição de 1988. Esse processo se dá mediante submissão do país aos ditames dos agentes financeiros internacionais, bem como da sua inserção numa condição subordinada na globalização, na qual impera o poder do mercado, inclusive, no direcionamento das políticas sociais.

Consoante o observado, a tendência tem sido a de restrição e redução dos direitos, com base no argumento da crise fiscal do Estado. De modo geral, as recomendações do Banco Mundial envolvem a focalização das políticas públicas na população mais pobre e a oferta de serviços no mercado para o segmento de melhor renda. Isso tem levado à transformação das políticas sociais em ações pontuais e compensatórias, condicionadas pela correlação de forças entre as classes sociais e segmentos de classe e do nível de consolidação da democracia (BEHRING; BOSCHETTI, 2006). Portanto, os direitos garantidos pelas políticas componentes da seguridade social são redefinidos, no sentido da seletividade e privatização, em detrimento das dimensões de universalização e estatização, defendidas durante a elaboração da Constituição de 1988.

Para os formuladores das políticas de contrarreformas do Estado, as políticas sociais devem ser compreendidas como atividades não exclusivas do Estado; devem ser subsidiadas pelo Estado, mas não, necessariamente, deverão ser desenvolvidas diretamente pelo poder público, ou, ainda, por instituições públicas estatais. Essa proposta põe em prática a estratégia de separação de funções de regulação e financiamento prioritariamente de responsabilidade do Estado, enquanto a prestação dos serviços deve ser realizada pelo setor privado, favorecendo o crescimento do mercado. Consoante a essa prerrogativa foram criadas as Organizações Sociais (OS) pela Lei $n^{\circ}$ 9.637/1998 ${ }^{9}$. Essas instituições configuramse como um modelo de organização pública

\footnotetext{
8 Conforme Bravo (2007), na segunda metade dos anos 1990, o projeto da reforma sanitária é questionado e consolida-se o projeto de saúde privatista. Este se pauta na política de ajuste, apresenta como tendências a contenção de gastos com a racionalização da oferta e descentralização com isenção de responsabilidades do poder central. Diante disso, a partir desse período, haverá uma disputa entre esses dois projetos políticos no âmbito da política de saúde. 9 Esta lei estabelece: Art. 1o O Poder Executivo poderá qualificar como organizações sociais pessoas jurídicas de direito privado, sem fins lucrativos, cujas atividades sejam dirigidas ao ensino, à pesquisa científica, ao desenvolvimento tecnológico, à proteção e preservação do meio ambiente, à cultura e à saúde, atendidos os requisitos previstos nesta Lei.
}

Serv. Soc. \& Saúde, Campinas, SP v. 13, n. 2 (18) p. 283-298 jul./dez. 2014 ISSN 1676-6806 
não estatal destinada a absorver atividades "publicizáveis" mediante qualificação específica (MARCH, 2012).

Do mesmo modo, algumas ações gestadas no governo Lula expressaram sua adesão às políticas de ajuste estrutural, de caráter neoliberal, como, por exemplo: aceitação do país como plataforma de valorização financeira internacional; liberalização do fluxo de capitais e de continuidade da privatização das políticas sociais, além da concepção destas como ações compensatórias de renda. Nesse mesmo sentido, estão inclusas as parcerias público-privadas ${ }^{10}(\mathrm{MARCH}, 2012)$.

De acordo com esse projeto neoliberal foi instituída a EBSERH ${ }^{11}$, a qual tem como pano de fundo o processo de contrarreforma, de privatização dos serviços sociais públicos, que passaram a ser delegados à iniciativa privada, por meio das mais distintas estratégias de ação.

Contudo, quanto à natureza da EBSERH, esta não corresponde ao mesmo formato de administração jurídica das Organizações Sociais ou das fundações estatais no tocante à sua gestão.

A EBSERH é entendida como um ente estatal, pois faz parte da administração pública indireta e sua gestão continua a ser pública. No entanto, o regime jurídico passa a ser híbrido. Já nas OS, a gestão é privada, com regime jurídico privado permeado por algumas orientações de direito público. Nessa perspectiva de análise, a EBSERH, por integrar a administração pública indireta, não poderia ser considerada como uma "privatização" em sentido técnico, por não implicar delegação de serviços e não se configurar com a desconstituição da natureza de "serviço público" dos serviços do SUS (SODRÉ et al., 2013).

Um elemento a merecer destaque para a discussão é a lei de criação da EBSERH, de $\mathrm{n}^{\mathrm{o}}$ 12.550/2011, onde se identifica ser esta subsidiada pelo inciso II do art. $5^{\circ}$ do Decreto-Lei ${ }^{\circ} 200$, de 25 de fevereiro de 1967, e pelo art. $5^{\circ}$ do Decreto-Lei $\mathrm{n}^{\circ}$ 900, de 29 de setembro de 1969. Com base em tais pressupostos, como observamos, são

\footnotetext{
${ }^{10}$ Segundo a Lei ${ }^{\circ} 11.079 / 2004$, que institui normas gerais para licitação e contratação de parceria público-privada no âmbito da administração pública, a parceria público-privada consiste no contrato administrativo de concessão, na modalidade patrocinada ou administrativa.

${ }^{11}$ A proposta de criação da EBSERH, na perspectiva de reordenar os hospitais universitários, foi pensada, a priori, em 2010, através da elaboração pelo Ministério da Educação (MEC) e o Ministério de Planejamento, Orçamento e Gestão (MPOG), da Medida Provisória n ${ }^{\circ}$ 520, assinada em 31 de dezembro, a qual autorizava o Poder Executivo a criar a Empresa Brasileira de Serviços Hospitalares. Todavia, a Medida Provisória ${ }^{\circ} 520$ é rejeitada no Senado e, em 2011, a presidente Dilma Rousseff, autoriza a criação da EBSERH, através da Lei $\mathrm{n}^{\circ} 12.550$, que se caracteriza por ser uma empresa com personalidade jurídica de direito privado.

Serv. Soc. \& Saúde, Campinas, SP v. 13, n. 2 (18) p. 283-298 jul./dez. 2014 ISSN 1676-6806
} 
legislações que remetem ao período da ditadura militar. Mencionada situação traz para o debate elementos para a reflexão acerca de uma proposta que, aparentemente, tem um ar de moderno, mas na verdade remete às legislações antigas para fundamentar a criação dessa empresa.

Em virtude desta configuração complexa, além de ser uma legislação recente, o entendimento sobre a referida empresa torna-se confuso. Tal proposta possui caráter ambivalente, pois pertence, ao mesmo tempo, à esfera pública e à esfera privada. Além disso, ao ser gerida com fundamento no direito privado, amplia a lógica do mercado no andamento dos serviços sociais públicos, como é caso da saúde.

Segundo Sodré et al. (2013), a EBSERH foi criada sob a alegativa de ter maior autonomia no uso dos recursos, legalização dos contratos de trabalho e aprimoramento do processo de gestão das instituições de ensino e saúde.

Uma das ideologias apregoadas em defesa das ações neoliberais refere-se à exigência de um novo modelo de gestão para o SUS, mais "flexível e moderno", sendo esse modelo a saída para a crise. No entanto, para essa perspectiva, a igualdade de direitos está assentada nas necessidades específicas, individuais; atenção focalizada; ações de responsabilização social; priorização das parcerias público-privadas; ênfase em novas formas de humanização e a "subjetivação" da participação política dos sujeitos sociais (MASSON, 2007).

\section{Resultados e discussões}

Consoante evidenciamos, nacionalmente, existem movimentos contra hegemônicos à proposta da EBSERH, como, por exemplo, a Frente Nacional contra a Privatização da Saúde, composta por diversos fóruns estaduais em torno da luta por um SUS $100 \%$ público, estatal e de qualidade. Mas a Frente não se posiciona contrária, somente, à EBSERH, e sim a toda e qualquer forma de privatização da política de saúde. Segundo manifesto da Frente Nacional contra a Privatização da Saúde, a EBSERH é inconstitucional e representa um ataque aos direitos trabalhistas, tendo em vista descumprir a decisão liminar do Supremo Tribunal Federal (STF), na Ação Direta de Inconstitucionalidade $\mathrm{n}^{\mathrm{o}} 2.135 / 2007^{12}$.

\footnotetext{
${ }^{12}$ Esta decisão restabelece o Regime Jurídico Único (RJU) previsto no art. 39 da Constituição Federal para contratação de pessoal na administração direta, autarquias e fundações mantidas com recursos do orçamento público que integram a administração indireta da União, Estados, Distrito Federal e Municípios.

Serv. Soc. \& Saúde, Campinas, SP v. 13, n. 2 (18) p. 283-298 jul./dez. 2014 ISSN 1676-6806
} 
No Ceará, há dois hospitais universitários vinculados à Universidade Federal do Ceará (UFC); a pesquisa desenvolveu-se em um deles. No que tange à administração financeira, os dois hospitais funcionavam independentemente. Todavia, em 2010, quando foi instituído o Programa Nacional de Reestruturação dos Hospitais Universitários $^{13}$ (REHUF), ambos passaram a formar o complexo hospitalar da UFC, atualmente, Hospitais Universitários.

Cabe ressaltar: a criação da empresa faz parte de um conjunto de medidas adotadas pelo governo federal para a reestruturação dos hospitais vinculados às instituições de ensino superior. No momento, a empresa é a responsável pela gestão dos hospitais por meio do REHUF, cujo objetivo é promover ações destinadas a garantir a recuperação física e tecnológica, além de atuar na reestruturação do quadro de recursos humanos das instituições. Ainda segundo a própria empresa, a rede de hospitais universitários federais ${ }^{14}$ é formada por 47 hospitais vinculados a 33 universidades federais (BRASIL, 2014).

A adesão formal da Universidade Federal do Ceará à EBSERH confirmou-se em uma reunião do Conselho Universitário (CONSUNI), no dia 26 de novembro de 2013. No entanto, anteriormente a isso, durante nossas observações e como exposto pelos próprios profissionais, antes dessa formalização, já se sabia que a ESBERH havia sido aprovada, pois os profissionais já sentiam sua atuação no interior da instituição.

No contexto atual, o clima entre os profissionais da instituição é de ansiedade e de incertezas sobre as mudanças advindas com essa nova gestão. O assunto mais comentado entre eles é o tão sonhado "concurso público", o qual será realizado por um órgão contratado pela EBSERH, com previsão de lançamento do edital em março de 2014, segundo informações da própria empresa. Como mencionado, o regime de contratação será o celetista.

Mediante a análise dos depoimentos dos sujeitos entrevistados podemos identificar a compreensão dos profissionais de saúde sobre a EBSERH. Em um dos aspectos indagados sobressaiu o fato dessa empresa ser ou não uma forma de

\footnotetext{
${ }^{13}$ Decreto $\mathrm{n}^{0} 7.082 / 2010$ que institui o Programa Nacional de Reestruturação dos Hospitais Universitários Federais (REHUF), dispõe sobre o financiamento compartilhado dos hospitais universitários federais entre as áreas da educação e da saúde e disciplina o regime da pactuação global com esses hospitais. ${ }^{14}$ As Universidades que estabeleceram contratos de adesão à empresa até o presente momento foram: UFPI, UNB, UFMA, UFTM, UFES, UFRN, UFGD, UFS, UFAM, UFMT, UFC, UFBA, UFPE, UFMG, UFSM, UFPB, UFMS, Univasf e a UFAL. Disponível em: <http://ebserh.mec.gov.br/>. Acesso em: 9 fev. 2014.

Serv. Soc. \& Saúde, Campinas, SP v. 13, n. 2 (18) p. 283-298 jul./dez. 2014 ISSN 1676-6806
} 
privatização do Sistema Único de Saúde, porquanto ela foi criada para gerir os hospitais universitários do país que prestam serviços sociais públicos de saúde.

Então, o que eu acredito que a EBSERH está vindo para privatizar o serviço da UFC, esse é o conceito que eu tenho da EBSERH. Então, eu pergunto assim: Será que a EBSERH vai melhorar o serviço? Eu não sei. Eu não posso te dizer que ela vai melhorar o serviço. Eu não tenho esta perspectiva, que vai melhorar o serviço (Entrevistado $n^{\circ} 1$ ).

Nesta fala, consoante o profissional afirma, a EBSERH é uma forma de privatização dos serviços. Todavia, ele se questiona se essa gerência vem com o intuito de melhorar a gestão dos serviços, mas não acredita nessa perspectiva de melhora. Segundo Sodré et al. (2013), a EBSERH está inserida num discurso gerencial industrial que propiciará a modernização da gestão dos recursos humanos. $\mathrm{Na}$ ótica do autor, o governo optou por uma privatização lenta, menos aguerrida e mais acanhada a fim de evitar a abertura de um diálogo mais aberto com a sociedade. Contudo, outro profissional não identifica a EBSERH como uma privatização:

Eu não vejo assim como uma privatização direta. Eu vejo como uma mudança de gestão que vai trazer muitos impactos, como a gente já conversou aqui. Mas, assim, a privatização, no sentido, hoje, da palavra, que a gente tem como aquela coisa que não [...] De dificuldade de acesso [...] Eu diria de saúde de poucos, eu não viria dessa forma (Entrevistado n ${ }^{\circ}$ ).

Este profissional não consegue identificar a EBSERH como uma estratégia de privatização direta, de restrição com relação ao acesso da população ao serviço público de saúde. Sobre esse aspecto, a Lei Federal $n^{\circ} 12.550 / 2011$, em seu art. $3^{\circ}$, $1^{\circ}$, estabelece que as atividades prestadas pela EBSERH estejam inseridas integralmente e exclusivamente no âmbito do SUS. Isto, a priori, inviabilizaria a prestação paralela de serviços privados de saúde.

Outro elemento trazido pelos profissionais é a perspectiva de gestão da EBSERH significar a inclusão de mecanismos de mercado no serviço público. Tal fato é identificado como algo positivo, pois na gestão privada existe a possibilidade de cobrar mais dos funcionários e, por conseguinte, elevar o quantitativo de procedimentos realizados.

Eu acho que essa é uma defesa do Ministério, é que a EBSERH por ela ter características de uma entidade particular, ela pode exigir mais do funcionário e daí terem melhor qualidade de serviço, melhor número de cirurgia, melhor número de consulta, melhor número de exames. Por quê? Porque ela vai gerir os hospitais de uma forma 
diferente do que é gerido hoje. Então eu acredito que melhore os serviços (Entrevistado $\left.n^{\mathbf{0}} 3\right)$.

É muito forte a tendência à cultura segundo a qual somente a gestão privada funciona, pois se acredita ter ela esse poder de cobrar mais dos seus funcionários e que isso melhora o quantitativo e também a qualidade do serviço prestado. Todavia, a nosso ver, subjacente a este discurso ideológico, há uma "satanização" do que é público e um "endeusamento" do que é privado a fim de reforçar e justificar o processo de privatização da coisa pública.

Ademais, o funcionário público é visto como alguém acomodado, que não gosta de trabalhar, de cumprir metas e, por conta da "estabilidade", estaria isento de demissão. Assim, de acordo com a fala seguinte, os profissionais geridos pela EBSERH seriam obrigados a se ajustar aos ditames da nova gerência:

[...] A diferença entre um funcionário da empresa pública e da empresa privada é muito grande, existem funcionários e funcionários. $\mathrm{Na}$ empresa privada você tem a obrigação de seguir como manda um figurino; numa empresa pública você tem também direitos e deveres e tem de fazer também como manda o figurino. Porém o funcionário público, por não ter medo de ser demitido, acaba relaxando (Entrevistado $\mathrm{n}^{\circ}$ 6).

Entretanto, é preciso sermos bastante cautelosos ao nos referirmos a essa "acomodação" dos funcionários públicos. Na nossa ótica, a questão da gestão dos recursos humanos, bem como dos demais impasses para se viabilizar uma saúde de qualidade para a sociedade poderia ser resolvida se o Estado assim decidisse. Evidentemente, a opção para lidar com esses impasses tem sido a transferência das suas responsabilidades diretamente à iniciativa privada ou indiretamente para as instituições públicas de direito privado com fundamento em um discurso gerencial modernizador.

Mais um elemento trazido pelos sujeitos da pesquisa refere-se ao vínculo empregatício dos futuros profissionais dos hospitais universitários, qual seja, o regime gerido pela Consolidação das Leis Trabalhistas (CLT).

\begin{abstract}
A gente se depara com essa proposta de uma empresa que vai contratar o servidor, o servidor não, o funcionário. Porque não é servidor, pelo vínculo celetista, mas pela CLT, tirando toda a condição de servidor dos hospitais universitários terem sua estabilidade, como a gente tem (Entrevistado n ${ }^{\circ}$ ).
\end{abstract}

Uma das prerrogativas da Lei $n^{\circ} 12.550 / 2011$ apresenta claramente a não intenção do governo federal em manter o regime estatutário dos servidores públicos dos hospitais universitários, pois como estabelece a referida lei em seu art. 10, o regime de Serv. Soc. \& Saúde, Campinas, SP v. 13, n. 18 p. 283-298 jul./dez. 2014 ISSN 1676-6806 
pessoal da EBSERH dar-se-á pela CLT. Uma das preocupações levantadas pelo profissional e que advém dessa condição celetista diz respeito à estabilidade.

Segundo afirmam Sodré et al. (2013), o regime de pessoal da EBSERH é de emprego público e não há nenhuma garantia de paridade remuneratória entre os servidores públicos federais, que poderão ser cedidos à EBSERH, e os empregados da própria EBSERH. Essa condição possibilita a convivência de trabalhadores com distintos tipos de contratação e salários, o que, por sua vez, implicaria maior fragilização na organização e nas lutas entre os trabalhadores da instituição.

Além disso, hoje, nos hospitais universitários, determinados funcionários atuam profissionalmente há 28 anos, contratados por uma entidade de natureza privada. Este é um dos elementos trazidos pelos profissionais participantes da pesquisa, pois diante da nova situação, verifica-se um impacto tanto referente aos serviços prestados quanto ao estado emocional desses profissionais em face da possibilidade de serem demitidos, inesperadamente, como podemos atestar na seguinte fala:

[...] Entristece-me muito sobre a questão da EBSERH aqui dentro [...] Eu tenho certeza que eles têm conhecimento sobre essas fundações em nível de Brasil, que não é uma realidade só de Fortaleza [...] Como resolver? Porque não é nada não, mas tem servidores com 27 anos, com 28 anos de dedicação a essa casa [...] E nos é bastante preocupante, a gente vê aqui nos corredores as pessoas bastante aflitas [...] O que vai acontecer depois que a EBSERH chegar? (Entrevistado $\left.n^{\circ} 5\right)$.

De acordo com Sodré et al. (2013), a legislação da EBSERH é omissa quanto à provável cessão dos trabalhadores terceirizados que atuam na instituição absorvida pela EBSERH. Assim, na percepção dos autores, não há garantia de manutenção ou renovação desses contratos, a denotar a fragilidade jurídica desses instrumentos.

O processo de adesão do hospital à EBSERH foi uma das questões dos profissionais participantes da pesquisa. Nesse aspecto, conforme eles expuseram, essa adesão deu-se sem a participação efetiva dos sujeitos envolvidos diretamente com esse processo, quais sejam, profissionais dos serviços, estudantes e demais segmentos. Além disso, ao serem convocados para uma aproximação ao tema, foi no sentido de tomarem conhecimento da proposta, porém a decisão de aceitação ou não da empresa já estava posta, como podemos apreender no trecho da entrevista a seguir:

[...] No caso da gente, nós fomos apresentados a essa proposta. Mas, em relação à participação de votação ou de, assim, opiniões sobre isso, ficou entre gestores e representantes de organizações [...] Eu acredito que foi uma coisa assim imposta totalmente [...] algo que já vinha Serv. Soc. \& Saúde, Campinas, SP v. 13, n. 2 (18) p. 283-298 jul./dez. 2014 ISSN 1676-6806 
sendo realizado no Brasil [...] Foi uma onda, e, assim, eu não sei até que ponto nós pegamos essa onda sem condições de retroagir ou de ir para frente (Entrevistado $\left.{ }^{\circ} 2\right)$.

Neste trecho, conforme o profissional pontua, a EBSERH foi como uma onda, sendo uma tendência verificada nacionalmente em outros estados da federação, e ele não sabe até que ponto a instituição poderia ou não aderir a essa empresa. Nessa fala, como podemos perceber, o profissional acaba considerando que dificilmente a UFC poderia ir de encontro à EBSERH, pois era algo já posto pelo governo federal e aqui restava apenas aceitar. Não há, portanto, uma perspectiva de contrassenso ou de contestação à instauração da EBSERH, mas um clima de acomodação e de adequação ao que já estava decidido.

Outro aspecto mencionado pelos profissionais refere-se às alterações nos processos de trabalho, as quais já vêm sendo sentidas com a mudança de gestão. Uma das consequências dessa mudança é o aumento do nível de cobrança no trabalho:

[...] Desde a primeira vez que a gente ouviu falar de EBSERH até hoje, porque ela não chegou de fato aqui, mas muitas coisas começaram a mudar, o que a gente nota é que o nível de cobrança começou a mudar pra gente que tá trabalhando [...] tem existido um nível de exigência maior (Entrevistado $n^{\circ} 8$ ).

Esse nível de cobrança vem acompanhado de uma estruturação dos serviços a partir da construção de fluxos, os quais estabelecem o direcionamento das ações prestadas pelos distintos setores do hospital. A nosso ver, a sistematização das ações, bem como a construção desses fluxos são extremamente importantes para uma melhor organização e planejamento na execução das atividades. Todavia, esse processo deve estar assentado em condições de trabalho que deem conta dessa estruturação a fim de que o trabalho desenvolvido não melhore somente quantitativamente, mas também qualitativamente. Além disso, a construção dessas propostas deve ser estruturada mediante a participação dos profissionais, no sentido de serem respeitados seus anseios, suas propostas de trabalho. Ademais, devem ocorrer em espaços deliberativos com vistas a serem encaminhadas e efetivadas.

Outros elementos apontados pelos sujeitos entrevistados são a autonomia universitária e a manutenção do tripé ensino, pesquisa e extensão, característico das Universidades Federais. Trata-se de pressupostos legais, garantidos constitucionalmente e que, de certa forma, causam bastante preocupação no que tange à sua efetivação a 
partir dessa nova gerência nos hospitais universitários. Dessa forma, o participante da pesquisa explicita sua preocupação quanto à manutenção desses princípios:

Que essa autonomia de gerenciamento das universidades e hospitais universitários fragiliza o tipo de ensino, pesquisa e assistência porque eu acho que ao mesmo tempo em que eles querem que a EBSERH venha pra sustentar esse tripé que existe, pra garantir o tripé, eu acho que isso não deixa claro (Entrevistado $n^{\circ} 7$ ).

Em tese, essa garantia está posta na Lei ${ }^{\circ} 12.550 / 2011$, pois, conforme seu art. $6^{\circ}$, a EBSERH deve respeitar o princípio da autonomia universitária, podendo prestar os serviços relacionados às suas competências mediante estabelecimento de contrato com as instituições de ensino. Evidentemente, como o preceito legal não é suficiente para sua garantia, devemos ter bastante cautela, porquanto a efetivação desse princípio estará condicionada a fatores de correlações de força, bem como da fiscalização e participação social dos segmentos envolvidos nesse processo.

Em suma, durante a pesquisa, como observamos, a proposta da EBSERH entre os profissionais ainda é uma incógnita. Além disso, existe fragilidade no conhecimento sobre a empresa, principalmente quanto às suas implicações jurídicas. A instauração dessa empresa, no hospital estudado, deu-se de maneira bastante velada, sem discussão aberta com a comunidade acadêmica e sem participação efetiva dos sujeitos envolvidos nesse processo. Tal fato acirrou um clima entre os profissionais de incertezas, dúvidas e questionamentos sobre os rebatimentos dessa proposta não somente no ambiente de trabalho, mas também na vida deles.

\section{CONSIDERAÇÕES FINAIS}

Diante das reflexões postas neste artigo, no nosso entendimento, a discussão sobre a EBSERH ainda está no nível de mais questionamentos do que de afirmativas ou de alegativas, pois é uma proposta em processo. Assim, mais do que apontar resultados, um dos objetivos do artigo é suscitar o debate sobre essa nova gestão em curso nos hospitais universitários do país, pois devemos estar atentos a essa proposta, sobretudo ante a fragilidade das legislações que lhe dão suporte.

No entanto, parece-nos claro que a EBSERH está consubstanciada no contexto da contrarreforma do Estado. Desse modo, se revela como mais uma estratégia de desconstrução dos princípios fundamentais do SUS, tendo em vista apresentar-se como um retorno à centralização das políticas sociais e uma ofensiva à participação e ao Serv. Soc. \& Saúde, Campinas, SP v. 13, n. 2 (18) p. 283-298 jul./dez. 2014 ISSN 1676-6806 
controle social. Cabe ressaltar: a proposta da empresa, segundo manifesto da Frente Nacional contra a Privatização da Saúde, foi rejeitada na $14^{\mathrm{a}}$ Conferência Nacional de Saúde, ocorrida em 2011, em virtude dos prejuízos que traria à sociedade em geral. Dessa maneira, a EBSERH é uma forma de privatização à qual devemos voltar um olhar mais cuidadoso pela particularidade evidenciada.

Conforme observamos, esta tem sido a saída encontrada pelo Estado com a justificativa de que o problema da saúde pública está na necessidade de um novo modelo de gestão mais "flexível e moderno", apto a solucionar os entraves à efetivação das políticas públicas universais e de caráter igualitárias. Nesse processo, o discurso ideológico é cada vez mais calcado nas nossas relações sociais mediante a instauração de "novos paradigmas" que estabelecem condições favoráveis para a defesa de propostas políticas de viés liberal-social, supostamente humanizadoras, que acabam velando as diferenças entre a dimensão pública e privada.

Como mencionamos, a lei de criação da EBSERH remete a legislações do período da ditadura militar, a denotar que a proposta de gestão formalizada com cunho modernizador está na verdade incutida de projetos ideológicos autoritários.

Diante do clamor da sociedade por grandes reformas no país, o Estado, com o intuito de responder aos grandes entraves na administração pública, traça medidas paliativas que apenas amortecem problemas de ordem estrutural. Contudo, não se mudam paradigmas de gestões sem se alterar as relações sociais que configuram e sustentam essa sociedade.

Ademais, identificamos fragilidades nesse processo de adesão das instituições à EBSERH, principalmente no tocante à participação dos sujeitos envolvidos diretamente nesse movimento. Em face do apreendido e com base na fala dos profissionais, essa adesão deu-se de forma lenta, gradual e silenciosa. Questionamos, pois, a não transparência nessas decisões, as quais não têm se caracterizado de modo mais horizontal e democrático.

\section{Referências bibliográficas}

ANDERSON, P. Balanço do neoliberalismo. In: SADER, E. et al. (Org.) Pósneoliberalismo: as políticas sociais e o estado democrático. Rio de Janeiro: Paz e Terra, 1995. p.09-23. 
BEHRING, E. R.; BOSCHETTI, I. Política social no Brasil contemporâneo: entre a inovação e o conservadorismo. In: BEHRING, E. R.; BOSCHETTI, I. Política social: fundamentos e história. São Paulo: Cortez, 2006.

BRASIL. Ação Direta de Inconstitucionalidade no 2.135/2007. Restabelece o Regime Jurídico Único (RJU) previsto no artigo 39 da Constituição Federal. Disponível em: <http://www.stf.jus.br>. Acesso em: 10 fev. 2014.

BRASIL. Constituição Federal de 1988. Disponível em: 〈http://www.planalto.gov.br〉 . Acesso em: 21 jan. 2014.

BRASIL. Decreto n 7082 de 27 de janeiro de 2010. Institui o Programa Nacional de Reestruturação dos Hospitais Universitários (REHUF). Disponível em: <http://www.planalto.gov.br>. Acesso em: 9 fev. 2014.

BRASIL. Empresa Brasileira de Serviços Hospitalares. Disponível em: <http://ebserh.mec.gov.br/>. Acesso em: 9 fev. 2014.

BRASIL. Lei das Organizações Sociais (OSs). Lei nº 9.637/1998. Disponível em: <http://www.planalto.gov.br/>.Acesso em: 28 jun. 2013.

BRASIL. Lei $\mathbf{n}^{\circ}$ 11.079/2004. Trata sobre as parcerias público-privadas. Disponível em: <http://www.planalto.gov.br>. Acesso em: 29 jun. 2013.

BRASIL. Lei $\mathbf{n}^{0}$ 12.550/2011 que autoriza a criação da Empresa Brasileira de Serviços Hospitalares (EBSERH). Disponível em: 〈http://www.planalto.gov.br〉. Acesso em: 4 jul. 2013.

BRASIL. Medida provisória $\mathbf{n}^{0} 520$ de 31 de dezembro de 2010. Autoriza o Poder Executivo a criar a Empresa Brasileira de Serviços Hospitalares (EBSERH). Disponível em: 〈http://www.planalto.gov.br>. Acesso em: 26 jan. 2014.

BRASIL. Resolução do Conselho Nacional de Saúde $n^{\mathbf{0} 466 / 2012}$. Trata sobre a pesquisa envolvendo seres humanos. Disponível em: <http://conselho.saude.gov.br/>. Acesso em: 3 fev. 2014.

BRAVO, M. I. S. Serviço Social e Saúde: desafios atuais. Temporalis. Revista da Associação Brasileira de Ensino e Pesquisa em Serviço Social - ABEPSS/ Política de Saúde e Serviço Social: impasses e desafios. Ano VII, n.13, (jan./jun.2007). São Luiz: Associação Brasileira de Ensino e Pesquisa em Serviço Social - ABEPSS, 2007.

SODRÉ, F.; LITTIKE, D.; DRAGO, L. M. B.; PERIM, M. C. M. Empresa Brasileira de Serviços Hospitalares: um novo modelo de gestão? Serviço Social \& Sociedade, São Paulo, n. 114, p. 365-380, abr./jun. 2013. 
FRENTE NACIONAL CONTRA A PRIVATIZAÇÃO DA SAÚDE. Manifesto da Frente Nacional contra a Privatização da Saúde à EBSERH. Disponível em: <http://www.contraprivatizacao.com.br>. Acesso em: 9 fev. 2014.

MARCH, C. A Empresa Brasileira de Serviços Hospitalares, universidades públicas e autonomia: ampliação da subordinação à lógica do capital. In: Autonomia universitária e trabalho docente. Universidade e Sociedade. Ano XXI, nº49, jan. 2012.

MARTINELLI, M. L. O uso de abordagens qualitativas na pesquisa em serviço social. In: MARTINELLI, M. L. (Org.). Pesquisa qualitativa: um instigante desafio. (Série Núcleo de Pesquisa). São Paulo: Veras Editora, 1999.

MASSON, M. de F. A "terceira via" na reforma da saúde pública brasileira. Temporalis. Revista da Associação Brasileira de Ensino e Pesquisa em Serviço Social - ABEPSS/ Política de Saúde e Serviço Social: impasses e desafios. Ano VII, n.13, jan./jun. 2007. São Luiz: Associação Brasileira de Ensino e Pesquisa em Serviço Social - ABEPSS, 2007. 
